\title{
Android Tabanlı QR Kod Teknolojisi ile Desteklenen Envanter Takip Sisteminin Geliştirilmesi
}

\author{
Caglar Gurkan $^{1 *}$, Merih Palandoken ${ }^{1,2,3}$ \\ 1* İzmir Katip Çelebi Üniversitesi, Mühendislik ve Mimarlık Fakültesi, Elektrik Elektronik Mühendisliği Bölümü, İzmir, Türkiye, (ORCID: 0000-0002-4652-3363), \\ caglar.gurkan@outlook.com \\ 2 İzmir Katip Çelebi Üniversitesi, Yapay Zeka ve Veri Bilimi Uygulama ve Araştırma Merkezi, İzmir, Türkiye, (ORCID: 0000-0003-3487-2467), \\ merih.palandoken@,ikc.edu.tr \\ 3 İzmir Katip Çelebi Üniversitesi, Akıllı Fabrika Sistemleri Araştırma ve Uygulama Merkezi, İzmir, Türkiye, (ORCID: 0000-0003-3487-2467), \\ merih.palandoken@ikc.edu.tr
}

(1st International Conference on Applied Engineering and Natural Sciences ICAENS 2021, November 1-3, 2021)

(DOI: $10.31590 /$ ejosat.1014193)

\begin{abstract}
ATIF/REFERENCE: Gurkan, C. \& Palandoken, M. (2021). Android Tabanlı QR Kod Teknolojisi ile Desteklenen Envanter Takip
\end{abstract} Sisteminin Geliştirilmesi. Avrupa Bilim ve Teknoloji Dergisi, (28), 1229-1232.

$\ddot{O} \mathbf{z}$

Son yıllarda teknolojinin gelişmesi ile birlikte günlük hayatımızdaki birçok aktivite daha kolay hale gelmiştir. Bu teknolojik gelişmeler, günlük hayatımıza ek olarak endüstride de bir dönüşüm dönemini başlatmıştır. Teknolojik dönüşümün bir sonucu olarak ise endüstrideki dijitalleşme önemli ölçüde hızlanmıştır. Böylelikle akıllı fabrika terimi ortaya çıkmıştır. Nesnelerin interneti ise akıllı fabrikaların en önemli teknolojik bileşenlerinden biridir. Bu çalışmada, akıllı fabrikalardaki envanterin takibini kolaylaştırmak ve zaman kazancını sağlamak amacı ile uçtan uca bir sistem tasarımı önerilmiştir. Bu sistem tasarımının geliştirilmesi için QR kod tasarımları, Android mobil sistem teknolojileri ve Firebase kullanılmıştır.

Anahtar Kelimeler: Android, Envanter takip, Firebase, Nesnelerin interneti, QR kod.

\section{Development of Inventory Tracking System Supported by Android- Based QR Code Technology}

\begin{abstract}
In recent years, with the development of technology, many activities in our daily life have become easier. These technological developments have started a transformation era in the industry in addition to our daily life. As a result of the technological transformation, digitalization in the industry has considerably accelerated. Thus, the term smart factory emerged. The Internet of Things is one of the most important technological components of smart factories. In this study, an end-to-end system design has been proposed in order to ease the tracking of the inventory and save time in the smart factories. QR code designs, Android mobile system technologies, and Firebase were used to develop this system design.
\end{abstract}

Keywords: Android, Inventory tracking, Firebase, Internet of things, QR code.

\footnotetext{
* İlgili Yazar: caglar.gurkan@,outlook.com
} 


\section{Giriş}

Envanterin takibi üretim tesisleri açısından oldukça önemli bir konudur. Son birkaç on yıl öncesine kadar envanterin takibi süreci kağıt tabanlı kayıt sistemleri ile manuel olarak işletilmekteydi. Fakat daha sonra Bernard Silver tarafindan 1948 yılında barkod teknolojisi ilk kez tanıtılmıştır (Sri Krishna Kumar et al., 2015). Bu teknolojik yenilik ile birlikte envanter takip sistemleri şirketler ve akademisyenler tarafindan dikkat çekici bir araştırma alanı olarak nitelendirilmiştir. Ek olarak envanterin takibi bir karar verme aracı olarak da nitelendirilebilmektedir. Bunun nedeni ise üretim tesislerindeki iş akışı içerisindeki envanterin takip edilmesinin önemidir (Kittiwan Nimkerdphol et al., 2018).

QR kod teknolojisinin kullanım alanı, Android ve iOS işletim sistemine sahip kamera donanımlı mobil cihazların günlük hayattaki öneminin artması ile birlikte genişlemiştir (Cox \& Shiffler Dean, 2014). Bu bağlamda literatürdeki mevcut çalışmalar şu şekildedir. Rusya'da Volgograd Üniversitesinde mevcut eğitim ve öğretim sistemini iyileştirmek amacıyla QR kod tabanlı bir uygulama geliştirilmiştir. Bu uygulama, öğrencilerin interaktif olarak öğrenmesini sağlayan artırılmış gerçeklik destekli oyunlara erişiminin sağlanmasında kullanılmıştır (Korobov, Epinina, \& ..., 2016). Hendry ve ark. tarafindan yapılan çalışmada, üniversitelerde öğrenci yoklama alınması sürecinin hızlandırılması amaciyla QR kod teknolojisi tabanlı bir sistem tasarımı geliştirilmiştir (Hendry, Rahman, 2017).

$\mathrm{Bu}$ çalışmanın başlıca amacı ise, Endüstri 4.0 kapsamında sanayideki dijital dönüşüme katkı sunmaktadır. Bu bağlamda, akıllı fabrikalardaki envanterin takibini sağlamak amacı ile bir sistem tasarımı önerilmiştir. Bu sistem tasarımının oluşturulması için Android tabanlı QR kod teknolojisi kullanılmıştır. Böylelikle ilgili envanteri alan kişinin ad ve soyad bilgisine ek olarak envanterin alınma zamanı bilgisi Android mobil cihazların arayüzünden takip edilebilmektedir.

Çalışmanın geri kalan bölümü şu şekilde düzenlenmiştir; kullanılan yöntemler 2. bölümde sunulmuştur, elde edilen sonuçlar 3.bölümde aktarılmıştır, gelecek çalışmalar da dahil olmak üzere çalışma hakkındaki son bilgiler ise 4. bölümde sunulmuştur.

\section{Materyal ve Metot}

Envanter takip sisteminin oluşturulması için kullanılan yöntemler bu bölümde sunulmuştur.

Python programlama dilinde qr kütüphanesinin kullanılmasıyla Spyder tümleşik geliştirme ortamında (IDE) QR kod tasarımları oluşturulmuştur. QR kodların içerisine 'alınan cihaz: cihazın adı' veya 'bırakılan cihaz: cihazın adı' formatına sahip olacak şekilde bilgiler gömülmüştür. Daha sonra QR kodlar 300x300 piksel olarak yeniden boyutlandırılmış ve '.png' uzantısıyla kaydedilerek QR kod oluşturma süreci tamamlanmıştır. Matkap, multimetre ve tornavida setinin bırakılması ve alınması olmak üzere iki farklı formatta oluşturulan QR kod tasarımları Şekil 1'de gösterilmiştir.

Android tabanlı mobil uygulama ise Android Studio IDE'sinde Java programlama dili kullanılarak geliştirilmiştir. RelativeLayout ve LinearLayout, Android XML yapısında yerleşim türü olarak kullanılmıştır. Bu yerleşim türleri içerisinde CardView, TextView, ImageView, ScrollView ve Button gibi e-ISSN: 2148-2683
Android bileşenleri kullanılarak mobil uygulamanın arayüz tasarımı oluşturulmuştur. Firebase ise gerçek zamanlı veritabanı olarak çalışmaya dahil edilmiştir. Ad ve soyad bilgisi olmak üzere envanteri alan veya bırakan kişinin takip edilmesi için mobil uygulamaya kayıtlanma süreci eklenmiştir. Ek olarak envanterin alınma veya bırakılma saatinin de takip edilebilmesi için calendar kütüphanesi kullanılmıştır. Android tabanlı QR kod okuyucusunun oluşturulması aşamasında ise üçüncü parti kütüphaneler kullanılmıştır.

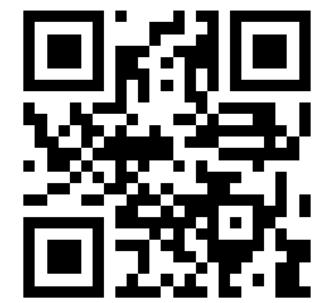

(a)

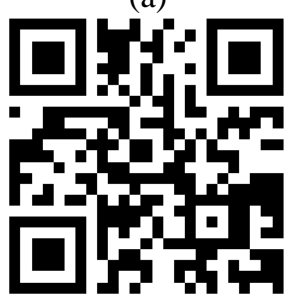

(c)

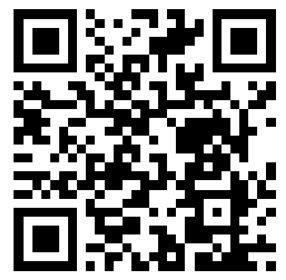

(e)

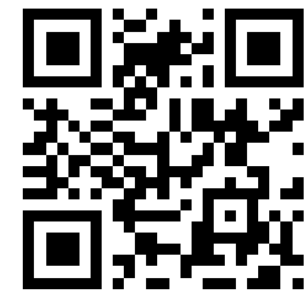

(b)

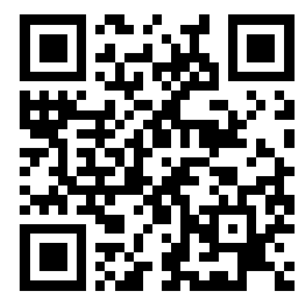

(d)

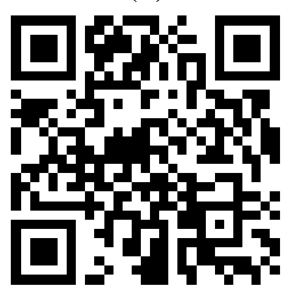

(f)
Şekil 1. (a) Matkap alımı için tasarlanan QR kod, (b) Matkap

bırakımı için tasarlanan QR kod, (c) Multimetre alımı için tasarlanan QR kod, (d) Multimetre bırakımı için tasarlanan QR

kod, (e) Tornavida seti alımı için tasarlanan QR kod, (f)

Tornavida seti bırakımı için tasarlanan QR kod

Android tabanlı mobil uygulama aracılığıyla QR kodların okutulması sonucunda envanterin takibi için iki farklı durum aşağıdaki gibi oluşturulmuştur;

a) Envanter alma işlemi: Oluşturulan QR kodun okutulması sonucunda envanteri alan kişinin ad ve soyad bilgisine ek olarak envanterin alınma zamanı bilgisi Firebase gerçek zamanlı veritabanına aktarılmıştır.

b) Envanter birakma işlemi: Oluşturulan QR kodun okutulması sonucunda envanteri bırakan kişinin ad ve soyad bilgisine ek olarak envanterin bırakılma zamanı bilgisi Firebase gerçek zamanlı veritabanına aktarılmıştır. Ayrıca bu aşamada, veritabanındaki ilgili envanterin alınma işlemi bölümüne 'Cihazı alan kişi bulunmamaktadır. Envanteri kontrol ediniz’ şeklinde bir uyarı yazısı gönderilmiştir.

Ek olarak envanteri alan kişiyi öğrenmek içinde bir arayüz tasarımı oluşturulmuştur. Bu aşamada veritabanı sorgu yöntemleri kullanılmıştır. Böylelikle arayüzde envanteri alan kişinin ad ve soyad bilgisine ek olarak envanterin alınma zamanı gözlemlenebilmektedir. Ayrıca, eğer envanter herhangi bir kişide değilse arayüzde 'Cihazı alan kişi bulunmamaktadır. Envanteri kontrol ediniz’ şeklinde bir uyarı yazısı gözlemlenmektedir. Şekil 
2'de oluşturulan veritabanı için 'parent-child' yapısı gösterilmiştir.

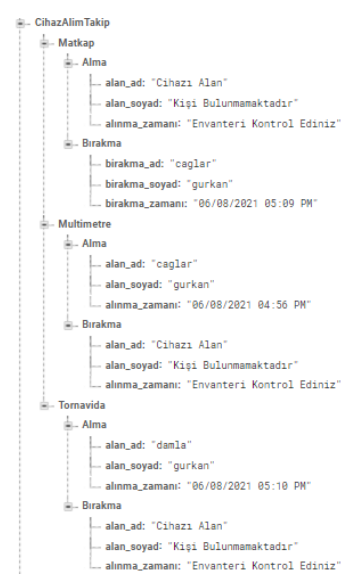

Şekil 2. Veritabanına ait 'parent-child' yapısı

\section{Bulgular ve Tartışma}

Çalışmada elde edilen sonuçlar bu bölümde aktarılmıştır.

Matkap, tornavida seti ve multimetre olmak üzere üç adet cihazın takibi için oluşturulan arayüz Şekil 3'de gösterilmiştir. Bu cihazların her biri arayüze CardView bileșeni kullanılarak dahil edilmiştir.

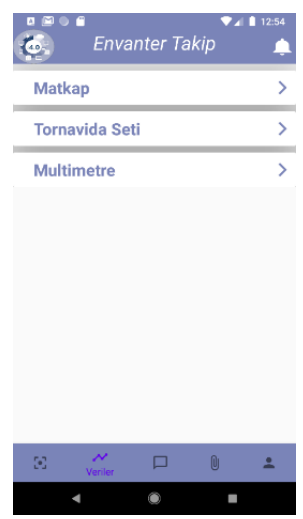

Şekil 3. Envanter takip sistemi arayüz tasarımı

Multimetre için kullanılan CardView bileşenine tıklanması sonrasında Şekil 4'de gösterilen arayüze geçilmektedir. Bu arayüzde cihaz alma, cihaz bırakma ve cihaz kimde ipucu ile birlikte kullanılan üç adet buton bileşeni yer almaktadır. Aynı arayüz tasarımı matkap ve tornavida seti cihazları için de oluşturulmuştur.

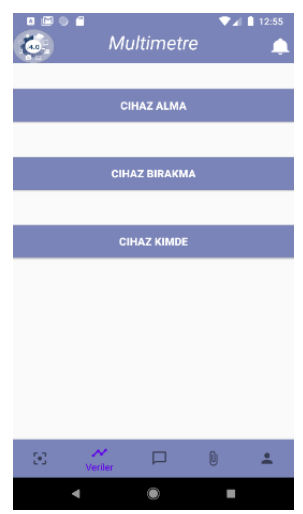

Şekil 4. Multimetre takip sistemi arayüz tasarımı
Arayüzde yer alan cihaz alma veya cihaz birakma butonlarına tıklanması sonrasında Şekil 5'te gösterilen arayüze geçilmektedir. Bu arayüzde 'lütfen qr kodu okutunuz' ipucu ile birlikte kullanılan bir buton bileşeni yer almaktadır. Bu butona tıklanması sonrasında Şekil 6'da gösterilen QR kod okutma işlemine geçilmektedir.

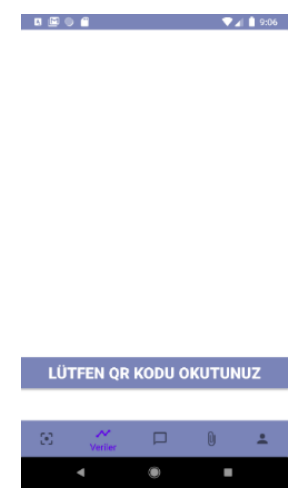

Şekil 5. QR kod okutma işlemi için oluşturulan arayüz tasarımı
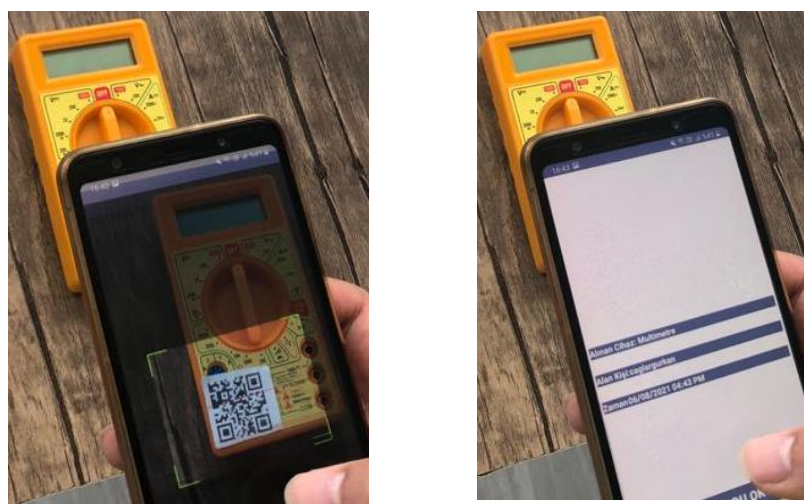

Şekil 6. QR kod okutma işlemi

Cihaz alımı için oluşturulan QR kodun okutulması ile elde edilen sonuç Şekil 7 (a)'da gösterilmiştir. Cihaz bırakımı için oluşturulan QR kodun okutulması ile elde edilen sonuç ise Şekil 7 (b)'de gösterilmiştir. Şekil 7 (a) ve (b)'de gösterilen arayüz tasarımlarında veritabanı sorgulama yöntemleri elde edilen sonuçların gözlemlenebilmesi 'alınan cihaz: alınan cihazın ismi' veya 'bırakılan cihaz: bırakılan cihazın ismi', 'alan kişi:', 'cihazı alan kişiye ait ad ve soyad bilgileri' veya 'cihazı bırakan kişiye ait ad ve soyad bilgileri', 'zaman:' ve 'cihazın alınma zamanı bilgisi' veya 'cihazın bırakılma zamanı bilgisi' olmak üzere beş adet TextView bileşeni kullanılmıştır.

Şekil 4'deki arayüzde yer alan ve cihaz kimde ipucu ile birlikte verilen butona tıklanması sonrasında Şekil 8 (a) ve (b)'de gösterilen arayüzlere geçilmektedir. $\mathrm{Bu}$ arayüz aracılığıyla cihazın $\mathrm{o}$ an kimde olduğunun ve alınma zamanının takibi sağlanmaktadır. Şekil 8 (a) ve (b)'de gösterilen arayüz tasarımlarında veritabanı sorgulama yöntemleri elde edilen sonuçların gözlemlenebilmesi 'cihazı alan kişiye ait ad ve soyad bilgileri' veya 'Cihazı alan kişi bulunmamaktadır' uyarı yazısı ve 'cihazın alınma zamanı bilgisi' veya 'envanteri kontrol ediniz' uyarı yazısı olmak üzere iki adet TextView bileşeninden oluşan CardView bileşeni kullanılmıştır. 


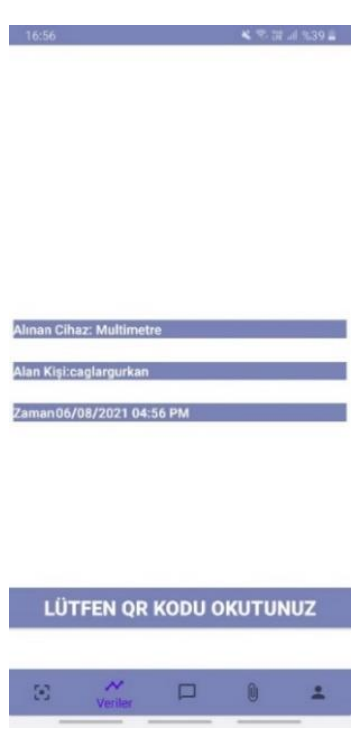

(a)

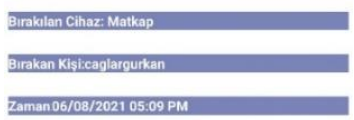

LÜTFEN QR KODU OKUTUNUZ

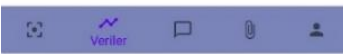

(b)

Şekil 7. (a) Cihazın alınması sonrasında elde edilen sonuçlar ve arayüz tasarımı, (b) Cihazın bırakılması sonrasında elde edilen sonuçlar ve arayüz tasarımı

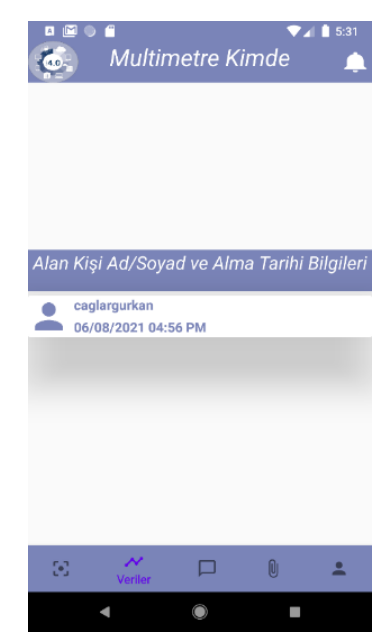

(a)
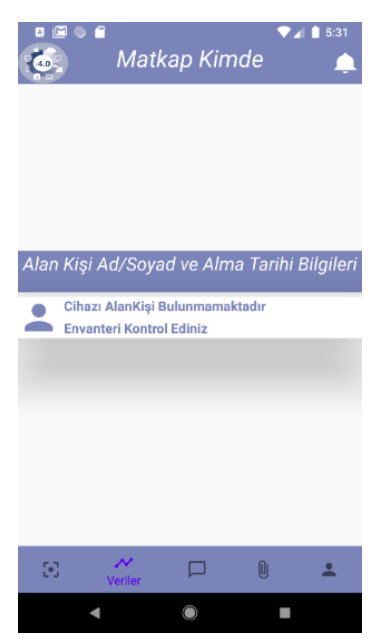

(b)

Şekil 8. (a) Cihaz herhangi bir kişideyken elde edilen sonuçlar ve arayüz tasarımı, (b) Cihaz herhangi bir kişide değilken elde edilen sonuçlar ve arayüz tasarımı

\section{Sonuç ve Gelecek Çalışmalar}

$\mathrm{Bu}$ çalışmada, akıllı fabrikalardaki envanterin takibi sağlanmıştır. Bunun için Android tabanlı QR kod teknolojisi kullanılmıştır. Böylelikle cihaz alımı esnasında ilgili cihaza ait alım QR kodunun okutulması sonucunda alan kişinin ad ve soyad bilgisine ek olarak cihazın alınma zamanı bilgisi Android mobil cihazların arayüzünden takip edilebilmektedir. Ek olarak cihaz bırakımı esnasında ilgili cihaza ait bırakma QR kodunun okutulması sonucunda envanter takip sistemi arayüzünde 'Cihazı alan kişi bulunmamaktadır. Envanteri kontrol ediniz’ şeklinde bir uyarı yazısı gösterilmektedir. Sonuç olarak, akıllı fabrikalardaki envanterin takibi sürecini kolaylaştıran ve zaman kazancı sağlayan uçtan uca bir sistem tasarımı oluşturulmuştur. Yapılacak gelecek çalışmalar arasında; QR kodun kullanımı ile takibi sağlanan envanterin sayısının artırılması, Android tabanlı mobil

uygulamanın iOS işletim sistemine sahip mobil cihazlar için de geliştirilmesi ve envarter takibinin web uygulaması ile de desteklenmesi yer almaktadır.

\section{Teşekkür}

Bu çalışma, İzmir Katip Çelebi Üniversitesi Bilimsel Araştırma Projeleri Koordinatörlüğü, Proje no: 2021-TYL-FEBE-0009 tarafindan desteklenmiştir.

\section{Referanslar}

Sri Krishna Kumar, S., Chandni, G., Meenal, A. L., Kalaimohan, T. S., Senthil Kumar, R., \& Sugavanam, K. R. (2015). BLE enhanced decentralised work time sheet and real time monitoring using smart id card. ARPN Journal of Engineering and Applied Sciences, 10(18), 8080-8084.

Kittiwan Nimkerdphol, D. R., Rd, N., Amphoe, T., Luang, K., Wat, C., \& Thani, P. (2018). Inventory Management System Using QR Code on Android a Case Study in Computer Engineering Department. In Journal of Electrical Engineering and Computer Sciences 3(1).

Cox, S., \& Shiffler Dean, R. E. (2014). Extent of QR Code Adoption by Consumers. International Journal of Business, 4(6), 2012-2015.

Korobov, S. A., Epinina, V. S., \& ... (2016). Implementation of QR-technology in academic process of management-education. European Journal of ..., 5.

Hendry, R. \& Rahman, M. (2017). Smart Attendance System Applying QR Code. Cpfd.Cnki.Com.Cn. https://doi.org/10.15242/iie.e0517002 